\title{
LA PERSPECTIVA DE GÉNERO DESDE EL ESTUDIO DE LA FAMILIA CUBANA
}

\author{
CRISTINA GarCÍA-MORENO \\ Universitat Rovira i Virgili
}

Recibido: $24 / 03 / 2014$

Aceptado: 12/05/2014

\section{Resumen}

Este trabajo presenta una investigación antropológica de carácter cualitativo que trata de mostrar la institución familiar y las relaciones de género, como inseparables del contexto sociocultural en el que se inscriben. Así, se tiene en cuenta de qué forma la dinámica y características de la familia se modelan en función de aspectos históricos, políticos, económicos e ideológicos. En particular, se analiza el caso cubano con el objetivo de averiguar hasta qué punto su pasado colonial y la incidencia de un Gobierno que, desde su instauración en 1959, proclamó su interés por lograr la igualdad entre géneros e incentivó la presencia de las mujeres en el espacio público, han incidido en el cambio o transformación de la familia y en la situación de la mujer cubana tanto dentro como fuera de la Isla.

Palabras clave: Cuba, familia, relaciones de género, España

\begin{abstract}
This work presents a qualitative approach to anthropological research that tries to show the family institution and the gender relationship as inseparable from the sociocultural context in which they exist. It considers how the dynamic and the characteristics of the family are modelled depending on historic, political, economic and ideological aspects. In particular, the Cuban case is analysed, in order to know how far its historical past as a colony and the influence of the Government (which, since 1959, showed interest in achieving a real equality on gender and encouraged the presence of women on all public aspects) have influenced the change or transformation of the family and the situation of the Cuban women on the island as well as in foreign countries.
\end{abstract}

Keywords: Cuba, family, gender relations, Spain. 



\section{Introducción}

En el planteamiento de este trabajo se ha partido de la importancia que adquieren los aspectos históricos, políticos, económicos e ideológicos tanto en la configuración de los modelos y características familiares, como en las relaciones conyugales y los roles de género. Partiendo de esta premisa, se analiza el caso cubano con el objetivo de averiguar hasta qué punto su pasado colonial y la incidencia de un Gobierno que, desde su instauración en 1959, proclamó su interés por lograr la igualdad entre géneros e incentivó la presencia de las mujeres en el espacio público, han incidido en el cambio o transformación de la familia y en la situación de la mujer cubana tanto dentro como fuera de la Isla.

Para ello, se analiza en primer lugar la tendencia a la matrifocalidad en el Caribe, fenómeno que tiene sus raíces históricas en el período colonial y que incidió de manera relevante en esa zona geográfica y en las estructuras y dinámicas familiares actuales. En segundo lugar, se recogen algunos de los aspectos que caracterizan a los núcleos familiares cubanos actuales, siendo precisamente uno de ellos el relevante y creciente incremento de los hogares en los que la mujer se presenta como «jefa de hogar». Seguidamente se ha pretendido conocer qué tipo de relaciones de género se establecen en las familias cubanas actuales y si el incremento de la presencia de las mujeres en el espacio público, ha implicado un cambio de valores respecto a los discriminadores roles de género tradicionales de gran parte de sociedades. Por último, y considerando las trayectorias migratorias de distintas tipologías de mujeres cubanas que optaron por migrar a España, se ha analizado hasta qué punto las relaciones de género han cambiado con la migración, bien sea en las prácticas cotidianas con sus parejas de origen, o bien en las establecidas a raíz del inicio de una nueva relación sentimental con un hombre español.

Respecto al trabajo de campo realizado, se ha sustentado en un abordaje cualitativo, de base etnográfica, que ha ayudado a comprender de qué forma los factores anteriormente mencionados han incidido en la situación de la mujer cubana y en las estructuras familiares de las que forma parte. De ahí que el enfoque teórico-metodológico más apropiado en esta investigación 
haya sido el biográfico, a través de la realización de entrevistas en profundidad en las que se ha enfatizado, sobre todo, en tres ejes temáticos: roles de género en las relaciones conyugales y familiares, valoración de la efectividad de la política gubernamental cubana en este sentido e incidencia de la migración en el mantenimiento o transformación de estos roles.

Así, se han realizado 31 entrevistas a mujeres cubanas inmigrantes de edades comprendidas entre los 19 y los 46 años y residentes en España, sin intención de que sus realidades fuesen representativas del conjunto de mujeres cubanas pero sí significativas de la diversidad de opiniones y de situaciones que podemos encontrar actualmente en España ${ }^{1}$. En su selección se han tenido en cuenta criterios como: la formación (seleccionando en similar medida a mujeres con estudios primarios, secundarios, técnicos o universitarios), la forma de salida (considerando fundamentalmente tres situaciones: las que emigran solas con un proyecto aparentemente individual, las que emigran con su pareja cubana de origen y las que lo hacen a través del matrimonio con un español), la situación legal y la antigüedad en España (más y menos de cinco años residiendo en España). Además, y con la finalidad de ampliar la heterogeneidad del grupo, el color de la piel se incluyó como otra de las variables consideradas, siendo 7 de ellas mulatas.

\section{La matrifocalidad en el Caribe}

La matrifocalidad tiene sus raíces históricas en el periodo colonial, y en todas las regiones del Caribe, presentándose como un modelo alternativo de familia originado en la clase baja negra, en la que los vínculos de consanguinidad eran más importantes que el lazo conyugal. Como señala Helen Safa², se presentaría como un modelo temprano de organización familiar encontrado en los pueblos subordinados de la América Latina colonial e incluso fuera del Caribe, en áreas como México, Brasil y América Central. En lugar del matrimonio o del vínculo conyugal, en el que están basadas las familias nucleares, en las familias matrifocales los lazos consanguíneos son más fuertes, sobre todo entre la mujer, sus hijos y sus parientes del sexo femenino. Estos lazos proporcionan a la mujer apoyo económico y emocional, así como protección en el caso de ruptura de una relación.

1. Los datos que aquí se recogen forman parte de una investigación más amplia. En concreto, la realizada a raíz del Proyecto Nacional de I+D+I (con ref. SEJ2006-10691) titulado «Trayectorias transnacionales y procesos glocales: familia, red social y formas de mediación» y dirigido por el Dr. Joan Josep Pujadas (URV).

2. SAFA, Helen. «La familia matrifocal y la ideología patriarcal en Cuba y el Caribe». Temas, 52 (2007), pp. 21-33. 
Perera y Meriño ${ }^{3}$ completan esta definición destacando que, desde su visión, en la matrifocalidad lo relevante es la forma de emparejamiento, es decir, mientras que el matrimonio conduce a la familia nuclear, el concubinato o consensualidad lo hace a la familia matrifocal. Ana Vera ${ }^{4}$, por su parte, define matrifocalidad como «familias donde la madre es la referencia central y el padre puede estar presente o ausente». Además lo considera como un fenómeno conectado a un gran número de divorcios y separaciones y con la exclusión del hombre de las tareas y responsabilidades domésticas. Por último, y según Helen Safa ${ }^{5}$, las sociedades matrifocales se caracterizarían por una alta actividad económica femenina (que conduce a la autonomía de la mujer), un bajo índice de matrimonios legales y altos índices de ilegitimidad y de hogares con mujeres como jefas de familia.

Un ejemplo claro de matrifocalidad en el Caribe es el estudio de las relaciones conyugales que realizó Larisa Lomnitz ${ }^{6}$ en uno de los suburbios de Ciudad de México. En él destaca que los roles conyugales se caracterizan por una clara división del trabajo entre actividades que, culturalmente, son consideradas masculinas o femeninas. El rol de la mujer es esencial en la estructura familiar y social, especialmente en las redes de intercambio con otros familiares y con la comunidad. Y aunque es cierto que generalmente es el hombre quién sale a ganar el sustento en el mercado, la mujer, además de colaborar en la economía familiar con su trabajo, es la base de la red de reciprocidad que permite la supervivencia en momentos de carencia.

Verena Stolcke ${ }^{7}$ afirma que, en el caso concreto de Cuba, el pasado colonial cubano se presenta como un importante condicionante del tipo de relaciones familiares y núcleos de convivencia que se detectan actualmente. Al revisar ese período llama la atención que la marginalización sexual de la mujer de color se manifestaba a través de la preponderancia de la consensualidad y/o el concubinato, lo que promovía el incremento de la matrifocalidad, que a menudo era resultado de la forma particular de iniciar uniones interraciales entre blancos colonizadores y mujeres negras (esclavas o no). En opinión de

3. Perera, Aisnara y Meriño, $\mathrm{M}^{\mathrm{a}}$. Ángeles. Esclavitud, familia y parroquia en Cuba: otra mirada desde la microhistoria. Santiago de Cuba, Editorial Oriente, 2008.

4. Vera, Ana. Cuba. Cuaderno sobre la familia. La Habana, Editorial Ciencias Sociales, 1997, pp.37.

5. SAFA, Helen. Op. cit.

6. LomnitZ, Larissa. Cómo sobreviven los marginados (decimocuarta edición). Madrid, Siglo XXI, 1998, pp.103.

7. STOLCKE, Verena. Racismo y sexualidad en la Cuba colonial. Madrid, Alianza Editorial (1992 [1974]), pp.199.

Feminismo/s 23, junio 2014, pp. 207-225 
$\mathrm{Safa}^{8}$, la diferenciación de las jerarquías de clase y raciales producidas durante este periodo de la historia de Cuba, junto con la mayor independencia económica de la mujer, motivó una mayor aceptación de las uniones consensuales y de los hogares matrifocales consanguíneos en lo que respecta al periodo prerrevolucionario. Pero lo que hace a Cuba interesante respecto al debate sobre matrifocalidad es que esta siguió incrementándose con el tiempo, incluso después de la Revolución de 1959 y a pesar de que el nuevo Gobierno reforzó el ideal de la familia nuclear como institución básica del socialismo y, al mismo tiempo, el del socialismo como protector de la familia, en contraste con la visión del capitalismo como destructor de vínculos familiares. Sin embargo, como se presenta a continuación, el porcentaje de hogares con mujeres como jefas de hogar y las uniones consensuales se han incrementado durante las últimas décadas.

\section{Características de la familia cubana actual}

El análisis de los grupos domésticos constituye un elemento importante en el desarrollo y en el contexto temático que sigue este trabajo ya que, siguiendo a Henrietta Moore ${ }^{9}$ «tanto la composición como la organización de los hogares repercuten directamente en la vida de las mujeres y, en particular, en su capacidad de acceder a los recursos, al trabajo y a la renta». De ahí que, en este apartado, se preste atención a algunos de los aspectos que caracterizan a los núcleos familiares cubanos en el momento actual y que podrían incidir en la situación presente y futura de la mujer cubana.

Ante todo, cabe destacar que se parte del concepto de familia entendido como «unidad de parentesco», es decir, todo vínculo establecido por consanguinidad o afinidad que no se reduce a la pareja conyugal ni a las relaciones de padres e hijos que viven juntos, sino que transciende la fragmentación y delimitación de los grupos residenciales. Stolcke ${ }^{10}$, coincidiendo con González Echevarría ${ }^{11}$ y Lomnitz ${ }^{12}$, concibe la familia como inseparable del contexto sociocultural en que se inscribe, del que forma parte y ayuda a reproducir, y su forma está determinada por multitud de factores políticos, históricos, económicos, ideológicos, etc. Esta visión se aproxima al caso particular de la realidad cubana y a las distintas formas de unión presentes en la isla actualmente.

8. SAFA, Helen. Op. cit.

9. MoOre, Henrietta L. Antropología y feminismo. Madrid, Cátedra, 1999, pp. 74.

10. STOLCKE, Verena. Op. cit.

11. GonZÁlez ECHEVARria, Aurora. «Familia», en Ángel Aguirre (coord.): Diccionario Temático de Antropología. Barcelona, Amarcombo, 1993, pp. 322-328.

12. LoMnitz, Larissa. Op. cit. 
En este sentido, es importante señalar que la crisis económica que afecta al país desde inicios de la década de los noventa, está provocando que la sociedad cubana se enfrente a todo tipo de dificultades, y que, desde ese momento, se iniciase un proceso de deterioro progresivo en lo que concierne a las condiciones de vida de las familias cubanas. Ante esta nueva situación, las familias han tenido que enfrentarse a un panorama social distinto que influye tanto en su funcionamiento como en su dinámica interna. Según $\mathrm{Chávez}^{13}$, algunos de los cambios demográficos destacables vinculados a la familia han sido:

- Intensificación de la caída de los niveles de fecundidad. La tasa bruta de reproducción (es decir, el número medio de hijas que tendría cada mujer) no llega a 0,8 desde $1992^{14}$. Esto lleva a pensar que una de las estrategias adoptadas por las familias para enfrentar la crisis podría ser la reducción del número de hijos.

- Rápido ascenso del número de matrimonios a inicios de la década ${ }^{15}$ y repentina caída posterior. Mientras que en 1991 la tasa de nupcialidad ascendió a un 15,1 por cada mil habitantes y en 1992 se llegó a un 17,7, para 1995 la tasa había descendido llegando a un 6,4 por cada mil habitantes. Los datos más recientes destacan que en 2012 fueron 55.759 los matrimonios celebrados en Cuba, lo que representa una tasa de 5,0 por cada mil habitantes ${ }^{16}$.

- Crecimiento de la consensualidad como forma de unión matrimonial lo que se evidencia en la reducción de las tasas de nupcialidad por edades y en el aumento del porcentaje de nacimientos correspondientes a madres «acompañadas»: del 57\% en 1987 pasó a representar el $63 \%$ en 1999. Los nacimientos procedentes de madres solteras (mujeres que no tienen vínculo marital en el momento en que nace su hijo) sólo constituían un $5 \%$ del total ${ }^{17}$.

- Incremento de los divorcios durante los primeros años de la crisis económica. Por cada 100 matrimonios celebrados en 1999 se produjeron

13. Chavez, Ernesto. «Población y crisis económica en Cuba: la familia y la dinámica demográfica del "Periodo Especial"», Ponencia presentada en el Taller Población y pobreza en América Latina. Buenos Aires, Argentina, 9-11 de noviembre del 2000.

14. OFICINA NACIONAL DE ESTADÍSTICA E INFORMACIÓN (ONEI). Anuarios Estadísticos de Cuba 2000, 2001, 2012 y 2013, La Habana, ONE [en línea] <http://www.one. cu> consultado el 03/02/2014.

15. Que algunos autores asumen a una estrategia familiar para hacer frente a la crisis, ya que el Gobierno incentivaba los matrimonios con ayudas materiales de distinta índole.

16. OFICINA NACIONAL DE ESTADÍSTICA E INFORMACIÓN (ONEI). Op. cit.

17. Ibíd. 
69 divorcios $^{18}$. Así, mientras que la tasa de divorcios en 1990 era de un 3,5 por mil habitantes, en 1992 representaba ya un 5,9 y en 1993 y 1994, aparecían tasas de un 6,0 y un 5,2 respectivamente. Revisando datos más recientes, se observa que esta tendencia al alza ha desaparecido con una tasa en 2012 del 2,9.

Por otra parte, es interesante señalar que se ha observado un incremento de los hogares encabezados por mujeres entre 1953 y 1981. En este periodo, la proporción de mujeres jefas del hogar, ha pasado de un $14 \%$ a un $28 \%{ }^{19}$. En 1995 ya representaban un 36\%, en 2002 un 40,6\% y, según los datos del último censo, en 2012 la cifra ascendió a un 44.9\%, lo que sugiere que la matrifocalidad está creciendo en Cuba. En cuanto al color de la piel, el índice de mujeres al frente del hogar continúa, todavía hoy, siendo más alto entre las mujeres negras que entre las blancas o mulatas, posiblemente porque las primeras mantienen un índice mayor de desintegración conyugal (20\%). Este tema lo conoce bien Diana, una de las informantes. Es hija de madre negra y padre mulato y su caso entraría a formar parte de estas estadísticas.

Tengo 3 hermanos por parte de padre pero esa es otra historia porque yo no tengo ni el apellido de mi papa, tengo el de mi madre nada más. Mi papá no me quiso reconocer (...). Él estuvo con mi madre un tiempo. Salió mi mamá embarazada y le dijo que no era de él. Así que nunca me crie con él (Diana, 37 años, Técnico en Contabilidad, 2 hijos)

Por último, destacar que aunque los índices de matrimonio fueron, históricamente, bastante altos en Cuba, sobre todo entre la población blanca, después de la Revolución disminuyeron, y lo siguieron haciendo después de la primera década de crisis económica. Así, en lugar de recurrir al matrimonio, muchos cubanos y cubanas viven actualmente en uniones consensuales, que se han incrementado entre los jóvenes y la población blanca, por lo que el matrimonio legal está perdiendo su legitimidad.

\section{Relaciones de género en la familia cubana}

La política social y la estrategia de desarrollo económico del gobierno cubano, desde el momento mismo de su instauración en 1959, ha tenido presente como objetivos fundamentales de su programa la eliminación de todas las formas de discriminación y explotación por motivos de clase, raza y sexo. En

18. Ibíd.

19. Alvarez, Mayda. «Familia e inserción social». Papers, Revista de Sociología, 52 (1997), pp.101-113. 
lo concerniente a las mujeres cubanas, este propósito intentaba favorecer sus condiciones de vida en general pero, sobre todo, en lo referente a aliviar sus responsabilidades en el ámbito reproductivo. De ahí que, desde el inicio del Gobierno actual se estableciese un soporte legal con la pretensión de sentar las bases de la igualdad de género ${ }^{20}$.

Partiendo de este hecho, el cambio político no sólo implicó una transformación económica y política de la sociedad como un todo, sino también un cambio radical de la familia cubana como organismo social y, en particular, de la mujer. Por primera vez, las mujeres asumieron nuevos roles en la esfera pública: aprendieron a dirigir, se formaron técnica y profesionalmente, se insertaron con éxito en el quehacer científico y alcanzaron una elevada presencia laboral, cultural y política. Por tanto, se vivió un cambio representado por el acceso masivo de la mujer a la educación y al mercado de trabajo ${ }^{21}$. Alicia, una de las mujeres entrevistadas, lo explicaba desde la experiencia de las mujeres que han estado más cerca de ella:

Mira, yo creo sinceramente, y estoy convencida, que el triunfo de la revolución en Cuba fue algo muy importante para la mujer. Antes, el mejor futuro para mi mamá era ser maestra y el de su hermana, mi tía, por el estilo. Era a lo más que podían llegar. Y ahora, mi tía es médico especialista y mi mamá es ingeniera ¿Comprendes? Y yo creo que esas mujeres que como mi mamá eran tan jovencitas cuando triunfó la revolución tuvieron la oportunidad de hacer muchas cosas, muchas cosas (Alicia, 39 años, Informática, Sin hijos)

A pesar de ello, y como nos recuerdan Aguilar, et al. ${ }^{22}$ y Holgado ${ }^{23}$, pese a la amplia presencia de la mujer en el espacio público y al trabajo educativoideológico que se ha venido realizando durante más de cinco décadas para intentar sentar las bases de una igualdad real, los patrones tradicionales de género aún ejercen una fuerte influencia en la conciencia social. La herencia cultural transmitió patrones y roles jerarquizados, asignados y asumidos por hombres y mujeres, que aún hoy se manifiestan en muchas familias donde prevalecen los estereotipos de género tradicionales. En el espacio privado, todavía se asigna a las mujeres las mayores responsabilidades relacionadas

20. Refiriéndonos, sobre todo, a la Constitución de la República Cubana de 1976 (capítulo VI, artículo 44) y al Código de Familia, aprobado en febrero de 1975 (Capítulo II).

21. Para más información ver: GARCIA-MORENO, Cristina y PUJADAS, Joan Josep. «No es fácil... y aquí tampoco. Trayectorias migratorias de mujeres cubanas en España». Revista de Dialectología y Tradiciones Populares (CSIC), Vol. 66, 2 (2011), pp. 455-486.

22. Aguilar, Carolina; POPOWSKI, Perla y Verdeses, Mercedes. «Mujer, periodo especial y vida cotidiana». Temas, 5 (1996), pp.11-17.

23. Holgado FernadeZ, Isabel. « ¡No es fácil! Mujeres cubanas y la crisis revolucionaria». Barcelona, Icaria, 2000. 
con la crianza y la educación de los hijos, la administración del hogar, las tareas domésticas, etc. De los escasos estudios encontrados sobre el tema, se ha seleccionado sobre todo un dato: que las mujeres en Cuba triplican el tiempo dedicado a las labores domésticas en comparación con los hombres. Las mujeres dedican como promedio 34 horas a la semana en tareas del hogar, mientras que el hombre lo hace alrededor de 12 horas y en condición de ayuda, sin responsabilidad ${ }^{24}$. Además, la distribución desigual de las tareas domésticas prevalece aunque se incremente el nivel de formación de ambos sexos e incluso tratándose de parejas con formación universitaria.

Todo en casa lo tenía que hacer yo, él no me ayudaba en nada y después no me daba tiempo a estudiar. Empecé a suspender, a suspender y no sé ni cómo aprobé (...). Y hablas el tema pero no... como siempre lo has visto pues tienes asumido que te va a tocar (Manuela, 29 años, Arquitecta, Sin hijos).

$\mathrm{Y}$, al parecer, en ocasiones el incremento de la formación de la mujer repercute de forma negativa en las relaciones de pareja, ya que se tiende a percibir como un reto entre sexos. Karol, a quien su apuesta por su mejora profesional le supuso una ruptura matrimonial, explica este aspecto de este modo.

Él ayudaba, pero es eso, ayudaba. Y si yo te ayudo es que solo hago algo, pero hace falta que se haga el 50\%. Es obligación de los dos (...). Las posibilidades a la mujer se las da el Estado pero a la que la mujer se desarrolla mucho, como puede ser mi caso, a nivel de pareja afecta al hombre, porque el hombre cubano es machista independientemente de la formación que tenga (Karol, 42 años, Bióloga, 1 hijo)

Para seguir con el análisis, se les preguntó a ellas, las protagonistas principales de este trabajo, por qué creían que en Cuba las mujeres mantenían la responsabilidad del trabajo reproductivo aun habiendo conquistado una representativa presencia en el sector productivo y habiendo logrado importantes cambios en el imaginario social. En varios casos, se ha hecho alusión a cómo influye en este aspecto la «imagen social», «el qué dirán», en un contexto inevitablemente marcado por el constante control social del vecindario. El hombre que realiza «tareas de mujer» es catalogado de «menos hombre». Enlazaríamos aquí con lo que señalaba Stolcke ${ }^{25}$ : es en este tipo de sociedades donde la opinión pública reina por encima de todo y el estatus social se logra a través de determinadas conductas. La opinión de los demás incide e influye

24. DiAZ, Elvira. «La invisibilidad y la visibilidad de la mujer en la historia de Cuba», en Collen Lundy y Norma Vasallo (ed.): Mujeres Cubanas, Canadá, Carleton University Graphic Services, 2001.

25. STOlCKe, Verena. Op. cit. 
en los comportamientos individuales. Y así lo explica Yolanda, otra de las informantes:

Yo creo que allí (en Cuba) está mal visto. No lo ve bien la gente. Allí la casa está siempre abierta y todo el mundo llega en cualquier momento, y te ve. Si él estaba fregando o planchando, imagina. (...) Y lo normal allí no es llamarse por teléfono y anunciar una visita. Las visitas llegan, te vaya bien o no. (Yolanda, 35 años, Aux. Enfermería, 1 hijo)

Además, en las entrevistas, nos comentan que el hecho de tener que compartir la vivienda con padres o suegros, por problemas económicos, incide en la reproducción de los roles de género tradicionales. La mayoría de ellas destaca lo negativo que resulta, en este aspecto, la convivencia con la generación anterior. «Es un poco difícil porque cuando tú no vives solo, el propio montaje familiar no lo permite» (Karol. 42 años. Bióloga. 1 hijo). Con frecuencia, son las propias madres (o suegras) las que impiden que sus hijos (varones) se impliquen en las labores domésticas, por lo que pretender cambiar ciertas normas incide negativamente en esa convivencia familiar. Al parecer, para evitar problemas, ellas tienden a asumir las tareas «de mujeres» y, por tanto, a reproducir roles.

Allí lo normal es que cuando te casas te vas a vivir con tus padres o con tus suegros porque el tema de la vivienda está imposible (...). Yo trabajaba, yo lavaba, planchaba y ayudaba a mi suegra en la limpieza. Mi suegro no hacía nada. Y mi marido, eso de que vamos a limpiar los dos, que va. (Yolanda, 35 años, Aux. Enfermería, 1 hijo)

La madre de él decía: «no, no que ya lo hago yo». Entonces quedaba muy mal que yo me quedara sentada (...). Al inicio lo hacía yo y ya le dije (a su marido): «no, tú también recoges y friegas, porque si no la tarea de la que te quiere librar tu madre termina siendo mía y tampoco es justo». Y es que las madres nuestras tenían almas de esclavas, lo típico de esa generación» (Carolina, 34 años, Farmacéutica, 1 hija)

Los aspectos que se vienen comentando ya aparecen en el interesante trabajo de Elisabeth Bott ${ }^{26}$ titulado Familia y red social: roles, normas y relaciones externas en las familias urbanas corrientes. La autora menciona la influencia de la organización de los hogares en la vida de las mujeres y, en particular, en la forma en como esta condiciona o asigna determinados roles domésticos. Pero Bott va aún más allá, ya que analiza cómo las formas de sociabilidad del grupo doméstico inciden en esa distribución de roles. Su hipótesis plantea que existe una relación directa entre la estructura interna de la familia y el

26. BOTT, Elizabeth. Familia y red social: roles, normas y relaciones externas en las familias urbanas corrientes. Madrid, Taurus, 1990.

Feminismo/s 23, junio 2014, pp. 207-225 
patrón de las relaciones externas de sus miembros, de ahí que el vínculo existente entre el marido y la mujer, y su cambio de roles, varíe en función del tipo de red social y familiar. Y, por lo que se ha podido comprobar, esta realidad también está presente en Cuba. Así, se observa que la igualdad conquistada en el ámbito público y legal, no ha estado acompañada de una situación similar en la práctica cotidiana y familiar, y las representaciones sobre el papel que hombres y mujeres han de encarnar formalmente en la sociedad siguen los cauces tradicionales.

En esta línea, resulta interesante el enfoque que el historiador cubano Julio Cesar González ${ }^{27}$ tiene al respecto. Menciona que el comportamiento socialmente aceptado para el cubano medio pasa por tener que cumplir su rol de buen padre proveedor, cuadro político abnegado, exitoso en su trabajo o estudios, mujeriego, músico, deportista o artista. Además, destaca que el mito del «príncipe azul» aún perdura en muchas mujeres. Y cabe mencionar que, con frecuencia, no son solo las madres las que persiguen ese ideal de hombre. También las jóvenes, la siguiente generación, tienden a buscar ese perfil determinado de hombre, «que las represente», que las proteja, que sea varonil. Marta, con su propia reflexión, recoge muy bien como todavía hoy prevalece un ideal de «hombre protector» que, en cierta medida, se configura a través de la influencia de las numerosas telenovelas que se emiten diariamente en Cuba. Gisela, a su vez, explica su sentir personal.

Los hombres tienden a ser protectores de la mujer de alguna manera, apadrinadores. No nos hemos despojado del todo de las figuras masculinas que venden las telenovelas y yo creo que eso marca mucho. La mujer cubana, como mujer, quiere un tipo que sea como más masculino, que guíe, que sea la fortaleza. No sé si es consciente o no pero lo veo en la mayoría de mis amigas de Cuba. (Marta, 36 años, Bioquímica, Sin hijos)

Mi chico no es celoso pero siempre está pendiente, y me gusta eso (...). Me gusta tener un tío al lado, que cuando entro en un sitio digan: «es guapo y además se ve macho». A las latinas nos gusta un poco el macho, que luego es verdad que muchos latinos con testosterona fallan de que les tienes que hacer las cosas pero bueno, nadie es perfecto (Gisela, 29 años, Médico, Sin hijos)

Hemos encontrado también un tipo de análisis (que hacen algunas de las informantes) que nos ayuda a entender un poco más otro de los aspectos que también plantea Julio Cesar González ${ }^{28}$. Y es que el autor destaca la contradicción que supone que una Revolución que rompió con los estereotipos más

27. GonZÁlez, Julio César. «Feminismo y masculinidad ¿Mujeres contra hombres?». Temas, 37-38 (2004), pp. 4-15.

28. Ibíd.

Feminismo/s 23, junio 2014, pp. 207-225 
heterogéneos, no haya podido modificar el modelo de roles de género tradicional. Los motivos que se vienen presentando parecen razones de peso para que las estructuras de desigualdad y el modelo patriarcal se hayan mantenido. Pero ha resultado también revelador el argumento que surge de algunas entrevistas. Y es que si una cosa hizo el gobierno revolucionario desde su implantación fue transmitir a la población la idea de que el proyecto político que se implantaba, además de ser innovador, permitía alcanzar altos niveles de éxito personal, social y económico. Todavía hoy, el noticiero diario se diseña para transmitir, en primer lugar, aquellos logros obtenidos en la isla (máximas de producción, premios educacionales, estadísticas sanitarias reveladoras) para, en un segundo bloque informativo, mostrar las barbaries que se van sucediendo en otros países (mortalidad infantil, atentados terroristas, hambruna, etc.). Como relata Andrea, a la sociedad cubana se le inculca los logros de la revolución. El discurso político interno proclama que en Cuba se tienen unos indicadores sociales, económicos, etc. que poco tienen que envidiar a países más desarrollados. También se proclaman los logros educativos y productivos y desde el sistema educativo se «inculca», ya desde los niveles de primaria, el desarrollo de la propia autoestima personal, el «valemos, podemos». Ante esta consideración, Andrea, con su interesante punto de vista, ofrece una nueva vía de reflexión desde una visión más psicológica y quizás inconsciente para las propias mujeres: la mujer cubana puede con todo, con el trabajo productivo y el reproductivo, con el cuidado de los hijos y otros familiares, «ella puede». Alicia, es otra de las que apoya esta teoría.

Es una de las pocas cosas que se le puede agradecer a Fidel, que te inculcó tanto que «tú vales, tú puedes, tú eres lo mejor». Porque en Cuba el discurso político es que los cubanos tenemos los mejores resultados, que somos los más preparados en educación, en sanidad.. (...). Tenemos una arrogancia que no creo que sea mala, te da fuerza para salir adelante. Y yo creo que en el caso de la mujer también tiene que ver con eso. Ellas pueden!!. Son demasiados años con eso (Andrea, 30 años, Técnico en Contabilidad, Sin hijos)

En el caso de una de mis amigas, su marido no hace nada, nada. (...). Y ella es de ese tipo de mujeres que hacen miles de cosas y que son súper jefas de todo. Es universitaria y del tipo de mujeres que se levanta a las cinco de la mañana y antes de irse a trabajar lo tiene todo hecho. (Alicia, 39 años, Informática, Sin hijos)

Son interesantes sus aportaciones en este sentido, y presentan una línea más ante la que reflexionar. Otras, por su parte, indican que la situación de desigualdad entre hombres y mujeres va cambiando poco a poco, sobre todo entre parejas en las que ambos miembros han cursado estudios universitarios. Nos comentan que ahora, cuando van a Cuba y hablan con las amigas que 
siguen allí, perciben ciertos cambios. Ciertas responsabilidades empiezan a ser asumidas por los hombres universitarios de las generaciones más jóvenes. Aunque, al parecer, aún queda mucho por hacer al respecto.

\section{Ser mujer que emigra: roles de género en el nuevo núcleo familiar}

La aplicación del enfoque transnacional ${ }^{29}$ en esta investigación ha ayudado a descubrir si se mantienen presentes o no estructuras de desigualdad de género de forma transterritorial. Como señalan Goñalons et $a l .^{30}$, las realidades transterritoriales son espacios en los que se pueden reproducir o reconfigurar las formas de desigualdad sobre la mujer, a la vez que son también espacios en los que es posible potenciar su emancipación y autonomía. Por lo tanto, la situación de la mujer migrante puede ser mejor comprendida desde una óptica transnacional que desde un análisis clásico centrado en la sociedad de destino.

Desde este punto de partida, una cuestión de análisis que se planteó era si la migración representaba una estrategia para escapar de situaciones de desigualdad de género en el contexto familiar o de pareja. En el caso de las mujeres entrevistadas, este tema no se ha presentado como un condicionante para su migración, o como una de las causas principales que las ha impulsado a migrar o, al menos, no ha sido una causa explícita. Además, del conjunto de mujeres entrevistadas, más de la mitad no tenían pareja en origen, en concreto dieciséis de ellas. Hablamos, por tanto, de solteras, separadas o divorciadas y, entre las que se encontraban en los dos últimos grupos, no se ha encontrado ningún caso en el que se ponga en evidencia que su emigración se haya producido como una forma de «escapar» y vivir una nueva vida tras una ruptura. Es más, explican que las separaciones y divorcios en Cuba forman parte de la cotidianidad cubana, así como segundas y terceras relaciones, por lo que se han «naturalizado» y se viven de forma menos traumáticas que en España. Tras esta aclaración, se destaca que, en general, se trata de mujeres que diseñan un proyecto migratorio en solitario y que, en su mayoría, no dejan cargas familiares en origen. Sus migraciones no se diseñaron con la finalidad de reagrupar a los miembros de la familia una vez en destino, sino que se trata de procesos individualizados.

29. Para más información ver: GARCiA-Moreno, Cristina y PuJADAS, Joan Josep. «El vivir transnacional de los inmigrantes cubanos en España». Migraciones, 32 (2012), pp. 73-102.

30. GoÑalons Pons, Pilar; FleCha, Ramón; SANTACRUZ, Iñaki y Gomez, Carlos. «Las aportaciones y los retos de la perspectiva transnacional: una lectura de género». Simposio internacional «Nuevos retos del transnacionalismo en el estudio de las migraciones». Barcelona, 14-15 de febrero de 2008. 
Ahora bien, en este apartado se presta atención a lo que ocurre una vez en España, con la formación de nuevas relaciones sentimentales o, en el caso minoritario de las que llegaron acompañadas de su pareja cubana, en cómo se afronta la relación en el nuevo contexto social y político. Respecto a la situación de aquellas mujeres que habían llegado a España a raíz del inicio de una relación sentimental con un hombre español (ocho de ellas), la mayoría habían tenido parejas anteriores en Cuba, con hombres cubanos, en las que, de una forma u otra, la desigualdad de género estaba presente. De ahí que interesara saber si una vez en España y con el inicio de su nueva relación sentimental con un español, esa tendencia se mantenía. Son distintos los discursos recogidos ante este tema y no hay una tendencia establecida. Algunas de ellas comentan que su nueva relación en España, con un español, dista mucho de las mantenidas con hombres cubanos, incidiendo, como lo hace Karol, en que la igualdad se ha establecido como una de las bases de la pareja en casi todos los aspectos. «Este apoyo que yo tengo de mi pareja. No, no, es otra filosofía. No, ahora estoy mejor. Ahora es compartir. Es otra percepción de lo que es llevar la casa. Es distinto» (Karol, 42 años, Bióloga, 1 hijo). Pero esta no ha sido la línea general ya que otras, como Ana, nos comentan que no han notado ninguna diferencia y que se están enfrentando a situaciones similares a las vividas con sus anteriores parejas. «No, en eso es como un cubano. No hace casi nada aquí. Tiene que verme muy atareada y eso. Él dice que soy la mujer y que soy la que lo tengo que hacer» (Ana, 21 años, Técnico Hostelería, Sin hijos).

Estas posturas también coinciden con un segundo caso, el de aquellas que emigraron solas e iniciaron una nueva relación de pareja después de llevar un tiempo viviendo en España (en la mayoría de los casos con un español), por lo que no hay mucho más a aportar en este sentido. Quizás si aclarar un aspecto: antes de iniciar esta nueva relación de pareja ya habían configurado su propio estilo de vida. La mayoría se había propuesto mejorar su situación académica o profesional, de ahí que muchas estuviesen estudiando o trabajando (muchas de ellas en trabajos acordes a su formación de origen) y ya habían decidido quedarse en España, bien porque no deseaban regresar a Cuba o bien porque se sentían cómodas en su nueva situación, con su nuevo estilo de vida. Si se menciona este hecho es para destacar que, como ellas mismas destacan, tomaron sus propias decisiones a la hora de gestionar su nueva vida y no estuvieron sujetas al inicio de la nueva relación sentimental.

Por otro lado, entre las que iniciaron un relación con un hombre español tanto desde origen como en destino, se ha encontrado un punto de conexión vinculado, sobre todo, al nivel de formación del varón: cuanto mayor es el 
nivel de formación del hombre, mayor es el grado de responsabilidad e implicación en las tareas reproductivas. Sin embargo, en estos casos, la mayor o menor formación de la mujer cubana respecto a sus parejas no parece ser un factor determinante: aunque la mujer tenga un nivel de formación universitario, los roles de género siguen siendo desiguales en aquellos casos en los que el hombre tiene un nivel de formación inferior.

En tercer lugar, se ha analizado la situación familiar de los siete casos en los que han sido los dos miembros de la pareja los que han emigrado e iniciado una nueva vida en España, centrando la atención en conocer si se han mantenido, reconfigurado o modificado los roles de género establecidos en origen. Como ellas mismas explican, en Cuba eran parejas que mantenían roles tradicionales en su contexto familiar y, en la mayoría de los casos, esta situación fue cambiando a medida que se prolongaba el periodo de convivencia en común en España. Los marcados roles de género presentes en su vida de pareja en Cuba (vinculados a las tareas domésticas y de cuidado de los hijos), una vez en España se han ido suavizando poco a poco. Nos comentan que ha influido mucho el hecho de vivir solos y ser conscientes de que no cuentan con ningún soporte familiar. También el saber que tampoco está presente el control social, es decir, que se vive «de puertas para dentro». Así lo explicaba Sandra: «¿El reparto de tareas en España? Muy bien. Aquí te puedo decir que es a la par. Mi marido hace cualquier cosa. Si tiene que lavar, si tiene que planchar, cualquier cosa. Lo compartimos 100\%». (Sandra, 33 años, Licenciada en Turismo, 1 hijo). Y así lo hace Yolanda: «Desde que estamos aquí él ha cambiado. En la casa vivimos nosotros dos y el niño. Planchar es lo único que no hace, lo demás todo. Lo de cocinar es casi de él. (...) Y de limpiar pues depende, compartimos (...). Sí, sí... aquí es diferente, es otra vida» (Yolanda, 35 años, Aux. Enfermería, 1 hijo).

Por último, respecto al grado de autonomía o emancipación alcanzado tras la migración, cabe recordar que son mujeres que ya trabajaban o estudiaban en origen y tenían unos ingresos. La mejora, una vez en España ha consistido, sobre todo, en conseguir un mejor salario, en mantener o en mejorar su estatus de partida, así como en haber logrado una mayor libertad de movimiento sin estar sujetas al control social o familiar.

\section{Conclusiones}

Resulta interesante observar como en la estructura familiar cubana actual ha incidido el pasado colonial de Cuba que, entre otras características, estuvo marcado por numerosas relaciones conyugales basadas en el concubinato y/o la consensualidad. Este hecho incidió, con el paso de los años, en un 
incremento de la matrifocalidad que, como se ha visto, no sólo afectó a Cuba sino a otros países caribeños que también vivieron los efectos del colonialismo. La matrifocalidad, que continúa presente en la sociedad cubana actual, otorga un importante protagonismo a la mujer en lo que respecta a la organización familiar, así como altas cuotas de independencia y de autonomía personal a la hora de tomar sus propias decisiones. En este sentido, resulta curioso que precisamente la autonomía ha sido uno de los aspectos que ha marcado las trayectorias migratorias de las mujeres cubanas que han formado parte de este estudio, ya que la mayor parte de ellas iniciaron proyectos migratorios individualizados.

Por otra parte, llama la atención que en Cuba en lo que respecta a la discriminación y desigualdad por género todavía queda mucho por hacer. Al contrario de lo que se podría pensar, pese a la amplia presencia de la mujer en el espacio público y al trabajo educativo-ideológico promovido por el Gobierno desde su instauración para intentar sentar las bases de una igualdad real, los roles tradicionales de género aún ejercen una fuerte influencia en la conciencia social. Además, al mismo tiempo que las mujeres obtenían una mayor representación social se incrementaba su carga de trabajo, ya que a la responsabilidad poco compartida del trabajo reproductivo, se sumaba la carga del trabajo en el espacio público. De nuevo, en el caso de la mujer cubana, reaparece el tan frecuente fenómeno de la «doble presencia» ${ }^{31}$. Por tanto, y coincidiendo con los resultados de otros trabajos previos ${ }^{32}$, la presencia en el espacio público, por sí misma, no ha implicado ni liberación ni necesariamente un cambio de valores. Tampoco el soporte de un reconocimiento legal. El concepto de igualdad cubano no connota similitud, sino que se refiere a igualdad de oportunidades o igualdad formal ${ }^{33}$.

En cualquier caso, cabe destacar que la migración de las mujeres cubanas entrevistadas no se ha presentado como una forma de huir de relaciones de pareja no deseadas, o al menos así lo han afirmado ellas. De hecho, no se ha detectado ningún caso en el que una separación sentimental o divorcio haya condicionado o incentivado su proyecto de salida o migratorio. Las que habían pasado por una ruptura de pareja lo habían hecho varios años antes y habían restablecido su vida en Cuba sin dificultad.

31. BALBO, Laura. «La doppia presenza». Inchiesta, 32 (1979). (traducción castellana en Borderías-Carrasco-Alemany (1994)).

32. FERREE, Myra. «Employment without liberation: Cuban women in the United States». Social Science Quarterly, 60 (1979) pp. 35-50 y MOORE, Henrietta L. Op. cit.

33. LuCiAK, Ilja. A. «Party and State in Cuba: Gender Equality in Political Decision Making». Politics \& Gender, Vol.2 (2005), pp. 241-263. 
Lo que no queda tan claro es si en la formación de sus nuevas parejas sentimentales, constituidas desde Cuba o bien después de haber vivido un tiempo en España, ha influido o no un posible imaginario sobre el hombre español y sobre relaciones más igualitarias. Lo cierto es que, exceptuando uno de los casos, tanto las que conocieron a un español en Cuba y decidieron venir a España como las que llegaron solas a España e iniciaron aquí una nueva relación, lo han hecho con un hombre español y no con uno cubano. Además, y respecto a sus nuevas relaciones, se ha encontrado un punto de conexión en todos los casos: cuanto mayor es el nivel de formación del hombre, mayor es su grado de responsabilidad e implicación en las responsabilidades reproductivas. Sin embargo, en estos casos, la mayor o menor formación de la mujer cubana respecto a sus parejas no parece ser un factor determinante.

Por último, mencionar la situación de aquellas mujeres que llegaron a España junto con su pareja cubana. Entre sus relatos aparece la idea de lo difícil que resulta en Cuba escapar de la presión y el control social que tiende a ejercer tanto el núcleo familiar (sobre todo por parte de mujeres de generaciones pasadas), como los miembros del contexto social más próximo. Una vez en España, nos comentan que han podido huir de «la atenta mirada de los demás», por lo que esos roles se han reconfigurado o modificado, y cada miembro de la pareja ha asumido nuevas responsabilidades más igualitarias. Esta realidad apuntaría en la línea de lo que ya mencionaba en su momento Elisabeth Bott ${ }^{34}$, a la que ya se hizo referencia en este trabajo: el vínculo existente entre el marido y la mujer, y su cambio de roles, varía en función del tipo de red social de cada cónyuge. Con la movilidad y los nuevos contactos sociales el entorno social se vuelve menos exigente y se detecta un mayor nivel de superación de los viejos esquemas de diferenciación de los roles de género. Y, al parecer, así ha sido.

\section{Referencias bibliográficas}

Aguilar, Carolina, Popowski, Perla y Verdeses, Mercedes. «Mujer, periodo especial y vida cotidiana». Temas, 5 (1996), pp.11-17.

Alvarez, Mayda. «Familia e inserción social». Papers, Revista de Sociología, 52 (1997), pp.101-113.

BALBO, Laura. «La doppia presenza». Inchiesta, 32 (1979). (traducción castellana en Borderías-Carrasco-Alemany (1994)).

BOTT, Elizabeth. Familia y red social: roles, normas y relaciones externas en las familias urbanas corrientes. Madrid, Taurus, 1990.

34. Bотт, Elizabeth. Op. cit. 
CHAVEZ, Ernesto. «Población y crisis económica en Cuba: la familia y la dinámica demográfica del "Periodo Especial"», Ponencia presentada en el Taller Población y pobreza en América Latina, Buenos Aires, Argentina, 9-11 de noviembre del 2000.

DIAZ, Elvira. «La invisibilidad y la visibilidad de la mujer en la historia de Cuba», en Collen Lundy y Norma Vasallo (ed.): Mujeres Cubanas, Canadá, Carleton University Graphic Services, 2001.

FERrEe, Myra. «Employment without liberation: Cuban women in the United States». Social Science Quarterly, 60 (1979), pp.35-50.

Garcia-Moreno, Cristina y PUjAdAs, Joan Josep. «El vivir transnacional de los inmigrantes cubanos en España». Migraciones, 32 (2012), pp.73-102.

— «No es fácil... y aquí tampoco. Trayectorias migratorias de mujeres cubanas en España». Revista de Dialectología y Tradiciones Populares (CSIC), Vol. 66, 2 (2011), pp. 455-486.

GONZÁlez ECHEVARria, Aurora. «Familia», en Ángel Aguirre (coord.): Diccionario Temático de Antropología, Barcelona, Amarcombo, 1993, pp. 322-328.

GONZÁLEZ, Julio César. «Feminismo y masculinidad ¿Mujeres contra hombres?». Temas, 37-38 (2004), pp. 4-15.

GoÑalons POnS, Pilar; FLECHA, Ramón; SANTACruz, Iñaki y GOMEZ, Carlos. «Las aportaciones y los retos de la perspectiva transnacional: una lectura de género». Simposio internacional «Nuevos retos del transnacionalismo en el estudio de las migraciones», Barcelona, 14-15 de febrero de 2008.

Holgado FernadeZ, Isabel. «iNo es fácil! Mujeres cubanas y la crisis revolucionaria». Barcelona, Icaria, 2000.

Lomnitz, Larissa. Cómo sobreviven los marginados (decimocuarta edición). Madrid, Siglo XXI, 1998.

LUCIAK, Ilja. A. «Party and State in Cuba: Gender Equality in Political Decision Making». Politics E Gender, Vol.2 (2005), pp. 241-263.

Moore, Henrietta L. Antropología y feminismo. Madrid, Cátedra, 1999.

OFICINA NACIONAL DE ESTADÍSTICA E INFORMACIÓN (ONEI). Anuarios Estadísticos de Cuba 2000, 2001, 2012 y 2013, La Habana, ONE [en línea] $<$ http://www.one.cu>, consultado el 03/02/2014.

PERerA, Aisnara y Meriño, $\mathrm{M}^{\mathrm{a}}$. Angeles. Esclavitud, familia y parroquia en Cuba: otra mirada desde la microhistoria. Santiago de Cuba, Editorial Oriente, 2008.

SAFA, Helen. «La familia matrifocal y la ideología patriarcal en Cuba y el Caribe». Temas, 52 (2007), pp. 21-33.

STOLCKE, Verena. Racismo y sexualidad en la Cuba colonia. Madrid, Alianza Editorial 1992 [1974].

Vera, Ana. Cuba. Cuaderno sobre la familia. La Habana, Editorial Ciencias Sociales, 1997. 